\title{
Sibel A. Ozkan: Electroanalytical Methods in Pharmaceutical Analysis and Their Validation
}

\author{
Hassan Y. Aboul-Enein
}

Published online: 6 June 2012

(C) Springer-Verlag 2012



\section{Bibliography}

Electroanalytical Methods in

Pharmaceutical Analysis and Their Validation Sibel A. Ozkan

HNB Publishing, New York, NY, USA, 2011, pp 350

ISBN:978-0-9664286-7-4

USD 99.75

Electrochemical detection provides an essential technique in the analysis of pharmaceuticals. Electrochemical analysis of active drugs is based on redox reactions depending on electron transfer pathways. Therefore, it is of interest to note that there is a close relationship between electrochemical and biological reactions.

This book discusses various electrochemical methods and their validation in drug analysis and their progress and great impact on analytical chemistry. Electrochemical analysis often offers advantages over other analytical methods, such as a high degree of accuracy, precision, selectivity and also low cost of operation.

The book consists of 9 chapters discussing various topics. Each chapter ends with a list of updated references.

Chapter 1 discusses the similarities and differences between various pharmacological classes of drugs versus chemicals. Chapter 2 provides the reader with background on electrochemistry and essential equations. An overview of electroanalytical experimental considerations and conditions is given.

Chapter 4 presents the different types of working electrodes, including chemically modified electrodes. Chapters 5 and 6 deal with linear sweep voltammetry, cyclic voltammetry and pulse voltammetric methods and their applications in pharmaceutical analysis, while Chapter 7 is devoted to various types of stripping voltammetric techniques.

Recent achievements in electrochemical analysis of pharmaceutical and biomedical chemistry are presented in Chapter 8, discussing its role in drug development, metabolite determination, oxidative stress, and electrochemical therapy. This is a very interesting chapter for electrochemists. Finally, Chapter 9 discusses the several validation parameters required for electrochemical analysis.

This book is well presented and well written; the figures are well illustrated. I highly recommend it to pharmaceutical and analytical chemists, researchers and graduate and postgraduate students.

The author is a highly qualified pharmaceutical analytical chemist with an impressive record of publication in the field of electrochemistry and is to be commended for a job well done. 